\title{
Endoscopic endonasal surgery for suprasellar meningiomas: experience with 75 patients
}

\author{
Clinical article
}

\author{
Maria Koutourousiou, M.D., ${ }^{1}$ Juan C. Fernandez-Miranda, M.D., ${ }^{1}$ \\ S. Tonya Stefko, M.D., ${ }^{1,2}$ Eric W. Wang, M.D., ${ }^{3}$ Carl H. Snyderman, M.D., M.B.A., ${ }^{1,3}$ \\ and Paul A. Gardner, M.D. ${ }^{1}$
}

Departments of ${ }^{I}$ Neurological Surgery, ${ }^{2}$ Ophthalmology, and ${ }^{3}$ Otolaryngology, University of Pittsburgh Medical Center, Pittsburgh, Pennsylvania

\begin{abstract}
Object. Following the introduction of the neurosurgical microscope, the outcomes in suprasellar meningioma surgery were dramatically improved. More recently, the neurosurgical endoscope has been introduced as a visualization option during removal of skull base tumors, both transcranially and endonasally. The authors retrospectively reviewed the effectiveness of endoscopic endonasal surgery (EES) in the management of suprasellar meningiomas.

Methods. Between 2002 and 2011, 75 patients (81.3\% female) with suprasellar meningiomas underwent EES at the University of Pittsburgh Medical Center. The authors present the results of EES and analyze the resection rates, visual outcome, and complications.

Results. Seventy-one patients presented with primary tumors, whereas 4 were previously treated elsewhere. Their mean age was 57.3 years (range 36-88 years), and most patients presented with visual loss (81.3\%). Tumors occupied the tuberculum sellae $(86.7 \%$ ) and planum sphenoidale $(50.7 \%)$, with extension into the optic canals in $26.7 \%$ (unilateral in $21.3 \%$ and bilateral in 5.3\%) and the pituitary fossa (9.3\%). Gross-total tumor resection (Simpson Grade I) was achieved in $76 \%$ of the cases in the whole cohort and in $81.4 \%$ of the patients in whom it was the goal of surgery. Tumor location and extension into the optic canals was not a limitation for total resection. Tumor size, configuration, and vascular encasement were significant factors that influenced the degree of resection $(\mathrm{p}<0.0001)$. Vision was improved or normalized in $85.7 \%$ of the cases. Visual deterioration following EES occurred in 2 patients $(3.6 \%)$. Complications included postoperative CSF leaks (25.3\% overall, $16.1 \%$ in recent years) resulting in meningitis in 4 cases. One patient had an intraoperative injury of the artery of Heubner resulting in associated neurological deficit. Another elderly patient died within 1 month after EES due to cerebral vasospasm and multisystem impairment. No patient developed postoperative cerebral contusions, hemorrhage, or seizures. During a mean follow-up period of 29 months (range 1-98 months), 4 patients have shown recurrence, but only 1 required repeat EES.

Conclusions. With the goal of gross-total tumor resection and visual improvement, EES can achieve very good results, (comparable to microscopic approaches) for the treatment of suprasellar meningiomas. Avoidance of brain and optic nerve retraction, preservation of the vascularization of the optic apparatus, and wide decompression of the optic canals are the main advantages of EES for the treatment of suprasellar meningiomas, while CSF leaks remain a disadvantage.
\end{abstract}

(http://thejns.org/doi/abs/10.3171/2014.2.JNS13767)

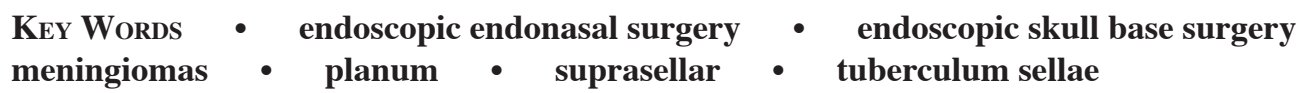

$\mathrm{D}$ ESPITE technological advances such as image guidance and the use of the operating microscope during the last decades, both of which have improved the surgical outcome in the management of suprasellar meningiomas, the treatment of these tumors remains challenging given the high risk of visual path-

\footnotetext{
Abbreviations used in this paper: ACA = anterior cerebral artery; $\mathrm{EEA}=$ endoscopic endonasal approach; EES = endoscopic endonasal surgery; GTR = gross-total resection; SIADH = syndrome of inappropriate antidiuretic hormone.
}

way involvement and vascular encasement of the paraclinoidal carotid artery or the anterior cerebral artery (ACA) complex. Various surgical approaches have been advocated to resect suprasellar meningiomas, with the subfrontal approach (unilateral or bilateral) being used in the early years of macroscopic neurosurgery and the pterional, frontolateral, or frontoorbital approaches being broadly adopted with the development of microscopic

This article contains some figures that are displayed in color online but in black-and-white in the print edition. 


\section{Endoscopic endonasal surgery for suprasellar meningiomas}

techniques. Recently, extended transsphenoidal surgery has become an alternative option for selected suprasellar meningiomas, although its benefits and limitations have yet to be firmly established. ${ }^{10,11,13,14,18,26,34,37}$

Endoscopic endonasal surgery (EES) provides panoramic visualization and wider access to the anterior skull base compared with the tunnel vision and speculum limitations of the microscopic transsphenoidal approach. Recent technological advances (angled endoscopes, specialized instrumentation, image guidance, neurophysiological monitoring of the brain) and skull base reconstruction techniques (vascularized nasoseptal flap) are routinely used and have extended the indications and success rates of EES. As a result, most suprasellar meningiomas, regardless of their location, extension, and optic nerve/optic canal involvement, can be removed with EES.

In this paper, we present our experience in the management of 75 patients with suprasellar meningiomas treated with EES. We analyze the benefits of this technique and study the variables that limit surgical success. To our knowledge, this is one of the largest surgical series of suprasellar meningiomas and represents the widest documented experience with EES.

\section{Methods}

\section{Patient Population}

With approval of the institutional review board, we retrospectively reviewed the medical files and imaging studies of patients with suprasellar meningiomas treated with EES at the University of Pittsburgh Medical Center between October 2002 and December 2011. Seventy-five patients with suprasellar meningiomas originating from the tuberculum sellae and/or planum sphenoidale were identified. One patient with meningiomatosis presented with 2 distinct suprasellar meningiomas of the planum sphenoidale and tuberculum sellae that were treated at the same time with a single EES. All meningiomas included in this study were benign (WHO Grade I). Patient age ranged from 36 to 88 years (mean 57.3 years) and there was a clear female predominance ( $81.3 \%$ female). Among the 75 patients, 71 had primary tumors $(94.7 \%)$ and 4 $5.3 \%)$ were previously treated elsewhere (2 with craniotomies, 1 with microscopic transsphenoidal surgery, and 1 with radiation therapy).

\section{Clinical Presentation}

The dominant clinical symptom at presentation was visual impairment affecting visual acuity, visual fields, or both, and occurred in 61 patients (81.3\%). Thirteen patients $(17.3 \%)$ complained of headaches. Changed mental status occurred in 2 cases $(2.7 \%)$ and seizures in 2 others, all of them with planum meningiomas and above average tumor size (as described below). One patient with a tuberculum sellae meningioma that extended into and occupied the pituitary fossa presented with hypopituitarism. Six patients (8\%) had asymptomatic, incidentally discovered tumors. In Table 1, clinical presentations are categorized according to the tumor location.

\section{Imaging Findings}

Preoperative MRI studies were available for every case and showed variable tumor size, configuration, and pattern of extension. Most of the meningiomas originated from the tuberculum sellae or from both the tuberculum sellae and planum sphenoidale (65 cases, 86.7\%), and only 10 were purely located on the planum sphenoidale. The outcome of EES for meningiomas originating from the cribiform plate even with extension to the tuberculum is the topic of another paper (in preparation). Although most of the tuberculum sellae meningiomas showed some degree of extension along the dura mater of the anterior wall of the sellae turcica, we found 7 cases that completely occupied the sella, displacing the pituitary gland.

The pattern of optic canal invasion was studied on finecut axial T1-weighted, postcontrast MRI; in patients with optic canal invasion $(n=20)$, the tumor entered the medial aspect of the optic canal in every case and involved both canals in 4 patients. Interestingly, 6 of the 20 patients with optic canal involvement had small unilateral tuberculum sellae meningiomas (Fig. 1), with early vision loss due to canal involvement. Optic canal involvement was confirmed intraoperatively in every case and defined as extension of the tumor beyond the anteriormost aspect of the optic strut (or lateral opticocarotid recess) in all 20 patients.

Tumor size varied from 0.7 to $5.2 \mathrm{~cm}$, with the smallest tumors representing tuberculum meningiomas and the largest planum or planum/tuberculum tumors. The shape of the free surface of the meningiomas was rounded in most of the cases $(69.3 \%$ ); among the 23 meningiomas with irregular configuration, 19 (25.3\%) showed engulfment of the surrounding arteries. Vascular encasement was studied on both MRI (including T2-weighted images) and fine-cut CT angiography. The T2-weighted MRI modality was particularly useful for assessing the integrity of the arachnoid plane between the tumor and the vessel and predicting intraoperative difficulties during dissection of the tumor from the vascular structures. Given the retrospective nature of this study, we were not able to reliably correlate the neuroimaging results with intraoperative findings. The presence of hyperostotic bone at the site of origin of the meningiomas was evaluated with preoperative CT scans of the head, which were available preoperatively in 63 patients. Table 2 summarizes the imaging findings in suprasellar meningiomas.

\section{Surgical Management}

All patients underwent purely EES with the previously described two-surgeon technique. ${ }^{19,21}$ The goal of surgery was decompression of the optic apparatus in all patients and gross-total resection (GTR) of the tumor in all but 5 cases. Reasons for planned near total/subtotal resection included elderly patients with comorbidities and clinical improvement after first-stage resection. In 13 patients we used staged approaches, with a second EES in 11 and combined EES/craniotomy in 2. Indications for craniotomy included tumor lateral to the optic nerves/ supraclinoidal carotid arteries and excessive scar tissue after first-stage EES. Of note, most of the staged surgeries took place in the early years of our experience with EES, 
TABLE 1: Clinical presentation of 75 patients with suprasellar meningiomas based on tumor location*

\begin{tabular}{llccc}
\hline & \multicolumn{4}{c}{ No. w/ Location (\%) } \\
\cline { 2 - 4 } Clinical Presentation & Planum & Planum/Tuberculum & Tuberculum & Total (\%) \\
\hline no. of pts & 10 & 28 & 37 & 75 \\
visual loss & $5(50)$ & $25(89.3)$ & $31(83.8)$ & $61(81.3)$ \\
headache & $4(40)$ & $3(10.7)$ & $6(16.2)$ & $13(17.3)$ \\
changed mental status & $2(20)$ & 0 & 0 & $2(2.7)$ \\
seizures & $2(20)$ & 0 & 0 & $2(2.7)$ \\
hypopituitarism & 0 & 0 & $1(2.7)$ & $1(1.3)$ \\
\hline
\end{tabular}

* pts = patients.

reflecting the learning curve associated with endonasal surgery as discussed below.

The surgery was customized for the location and extent of the tumor and included combinations of transsellar, transtuberculum, transplanum, transcribriform, and transorbital approaches (to remove the dural tail from the intrasellar, anterior marginal, and lateral skull base, respectively), including endoscopic optic nerve decompression whenever necessary (Table 3). The endoscopic endonasal approach (EEA) extended beyond the borders of the tumor in almost every case to access and remove the involved dura and abnormal bone to achieve true GTR (Simpson Grade I). As part of the initial management, 3 patients received adjuvant radiosurgery for residual tumor.

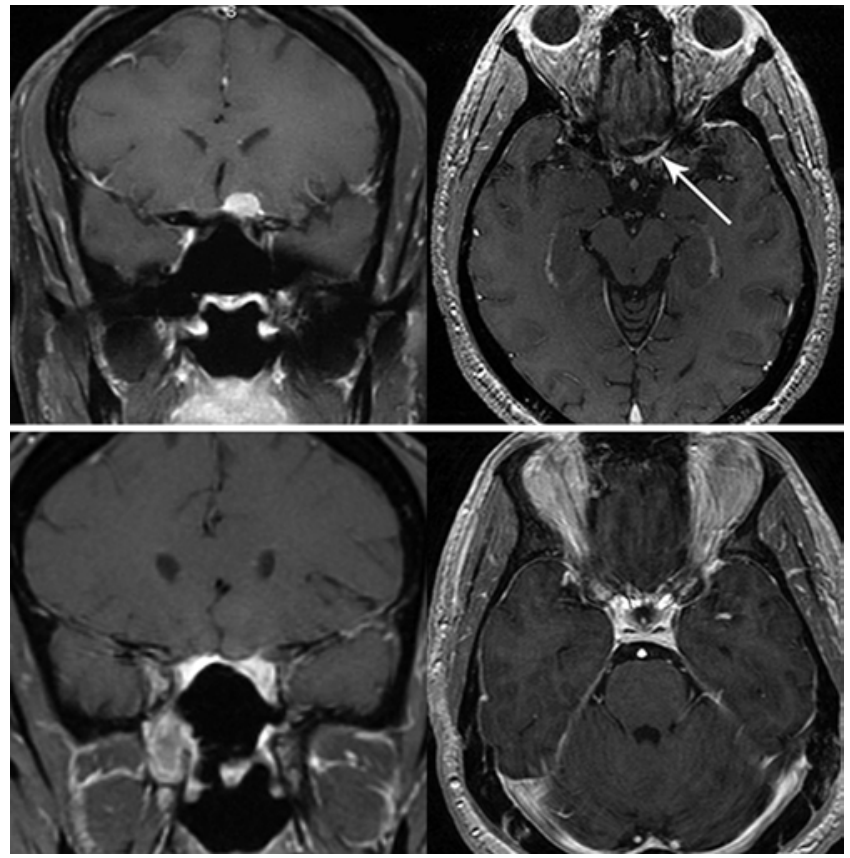

FIG. 1. Unilateral tuberculum sellae meningioma with optic canal involvement. Upper: Preoperative coronal and axial T1-weighted MRI studies obtained after administration of $\mathrm{Gd}$, demonstrating a unilateral tuberculum sellae meningioma of the left side measuring $1 \mathrm{~cm}$ in its maximum diameter, with extension along the medial wall of the optic canal (arrow on axial image). Six patients in total presented with similar unilateral tuberculum sellae meningiomas extending into the optic canal; in every case GTR was achieved, including resection of the tumor extension within the optic canal. Lower: Postoperative coronal and axial T1-weighted MRI studies obtained after GTR with EES.
Routine skull base reconstruction during recent years has consisted of an inlay of collagen matrix that is tucked under the margins of the dura and incorporates the entire defect; the entire bony defect is then covered by a vascularized nasoseptal flap, with care taken to approximate the edges of the flap with bone margins around the defect. Additional reconstructive material like degenerative tissue matrix (allograft) has been used in a minority of cases as an onlay deep to the flap if the flap is perforated or not big enough to cover the entire defect. Fat graft can also be applied as supplemental biological packing over the vascularized flap. All the reconstruction materials are held in place with a final layer of absorbable hemostatic collagen, tissue glue, absorbable gelatin sponge, and ei-

TABLE 2: Imaging characteristics in 75 suprasellar meningiomas

\begin{tabular}{lc}
\hline \multicolumn{1}{c}{ Parameter } & Value $(\%)$ \\
\hline location & \\
tuberculum sellae & $37(49.3)$ \\
planum/tuberculum & $28(37.3)$ \\
planum sphenoidale & $10(13.3)$ \\
extension & \\
intrasellar* & $7(9.3)$ \\
diaphragma sellae & $6(8.0)$ \\
optic canal, medial aspect & $20(26.7)$ \\
unilat & $16(21.3)$ \\
bilat & $4(5.3)$ \\
maximum diameter & \\
mean & $2.3 \mathrm{~cm}$ \\
range & $0.7-5.2 \mathrm{~cm}$ \\
free edge configuration & \\
rounded & $52(69.3)$ \\
multilobular & $23(30.7)$ \\
skull base anatomy & \\
hyperostotic bone attachment† & \\
relationship to surrounding arteries & 37 of $63(58.7)$ \\
vascular encasement & \\
\hline
\end{tabular}

* Almost all of the tuberculum sellae meningiomas had a dural tail along the anterior wall of the sella turcica; in this classification we define as intrasellar those tumors that completely occupied the pituitary fossa. † Preoperative CT available in 63 cases. 
TABLE 3: Endoscopic endonasal approaches used for the treatment of suprasellar meningiomas

\begin{tabular}{lc}
\hline \multicolumn{1}{c}{ EEAs } & No. of Cases $(\%)$ \\
\hline transsellar & $51(68)$ \\
transtuberculum & $69(92)$ \\
transplanum & $70(93.3)$ \\
transcribriform & $2(2.7)$ \\
transorbital & $3(4.0)$ \\
optic nerve decompression & $20(26.7)$ \\
unilat & $17(22.7)$ \\
bilat & $3(4.0)$ \\
\hline
\end{tabular}

ther Merocel tampons or a Foley catheter balloon; Foley balloon catheters are avoided in cases of completely decompressed optic nerves to avoid external compression of the exposed nerves.

\section{Evaluation of Surgical Results}

Clinical outcome after EES was assessed with postoperative visual tests (visual acuity and visual fields), clinical examination, and endocrine studies as indicated. All the visual changes following EES were objective based on formal visual tests, including visual field examination, performed by an experienced neuroophthalmologist.

The degree of tumor resection was evaluated on postoperative MRI sequences available in every patient in the immediate postoperative period, and confirmed with 3-month postoperative MRI in most cases (3-month studies were not available in 17 patients [22.7\%]). A GTR (Simpson Grade I) was defined as lack of residual tumor on radiographic images and was confirmed intraoperatively by inspection with $0^{\circ}$ and $45^{\circ}$ endoscopes; the endoscope allows a unique ability to inspect all regions of potential tumor involvement, even in areas that are not fully operable via this approach. When GTR was not achieved, the volume of residual tumor was measured using the mathematical formula of modified ellipsoid volume $\left[\left(A^{*} B^{*} C\right) / 2\right]$, where $A, B$, and $C$ were the maximum diameters of the meningioma in each of the 3 dimensions and the degree of resection was classified in comparison with the preoperative tumor volume as near total resection when $>90 \%$ of the tumor was removed, subtotal for resection of $50 \%-90 \%$, and partial if $<50 \%$ of the tumor was resected. Although GTR was not the goal of surgery in 5 patients, we analyzed our results with the same criteria in the whole cohort to avoid selection bias.

The length of follow-up was evaluated based on the most recent MRI session. Lack of available follow-up was usually due to distance of the patient from our center.

\section{Statistical Analysis}

The patient demographics, clinical presentation, tumor characteristics, surgical approaches, and outcomes were analyzed using descriptive statistics. The GTR rates for every studied tumor characteristic were compared using the chi-square or Fisher exact tests, as appropriate. A $p$ value $<0.05$ was considered statistically significant.
Data were collected using Microsoft Excel 2010 (Microsoft Corporation) and analyzed using SAS version 9.3 software (SAS Institute).

\section{Results}

\section{Clinical Outcome}

Among 61 patients who presented with a visual deficit, 5 were lost to postoperative ophthalmological evaluation. Among the remaining 56 patients, 48 (85.7\%) showed improvement or even normalization of vision following EES. In 6 cases vision remained unchanged, whereas 2 patients $(3.6 \%)$ experienced visual deterioration; in neither of these cases did vision return to the preoperative baseline. On another occasion, an intact patient experienced a transient visual deficit that recovered fully within days after surgery with steroid treatment. Visual outcome was not associated with tumor size; although visual improvement/normalization was slightly higher $(90.6 \%)$ in patients with tumor maximum diameter $<2.5$ $\mathrm{cm}$ compared with tumors $\geq 2.5 \mathrm{~cm}$ (visual improvement/ normalization $=79.2 \%$ ), this difference was not statistically significant $(\mathrm{p}=0.26)$. Among the 20 patients with tumor extension into the optic canals, 19 presented with visual impairment, and postoperative ophthalmological examination was available in 17; 16 of them (94.1\%) had improved vision after EES and 1 remained unchanged.

Preexisting headache improved or resolved in every case. Of the 2 patients who presented with changed mental status, 1 remained unchanged and 1 died of complications from vasospasm. The 2 patients with seizures continued to receive antiepileptic treatment following EES without any further deterioration. The patient who presented with hypopituitarism remained unchanged. Table 4 summarizes the clinical outcome.

It is important to note the recovery following EES. The overall mean length of hospital stay was 6 days (range 2-32 days). In the most recent years the main complication of a CSF leak has been reduced, allowing for earlier discharge. Since 2010, the mean length of hospital stay has been 3.5 days.

\section{Degree of Tumor Resection}

A GTR (Simpson Grade I) was achieved in 57 (81.4\%) of 70 patients in whom GTR was the goal of surgery and in $76 \%$ of all 75 patients. Among the remaining 18 patients, 9 had near total (12\%), 7 (9.3\%) had subtotal, and 2 $(2.7 \%)$ had partial resection.

To better understand the advantages and limitations of EES in suprasellar meningioma resection, we analyzed the rate of GTR according to tumor location, size, shape, extension into the optic canals, and evidence of vascular encasement. Table 5 summarizes the GTR rates of the 75 patients according to specific tumor parameters and includes the 5 patients in whom GTR was not the goal of surgery, as described earlier. Tuberculum sellae meningiomas were smaller tumors in our cohort; thus, a higher rate of GTR $(86.5 \%)$ was expected. The more extensive planum/tuberculum meningiomas had a lower GTR rate of $64.3 \%$ (Fig. 2). Despite this trend, GTR rates based on 


\section{Koutourousiou et al.}

TABLE 4: Clinical outcome after EES for suprasellar meningiomas

\begin{tabular}{lcccc}
\hline & \multicolumn{4}{c}{ Outcome $(\%)$} \\
\cline { 2 - 5 } \multicolumn{1}{c}{ Initial Deficit } & Resolved & Improved & Unchanged & Worsened \\
\hline visual loss $(\mathrm{n}=56)^{*}$ & $21(37.5)$ & $27(48.2)$ & $6(10.7)$ & $2(3.6)$ \\
headache $(\mathrm{n}=13)$ & $12(92.3)$ & $1(7.7)$ & 0 & 0 \\
changed mental status $(\mathrm{n}=2)$ & 0 & 0 & $1(50)$ & $1(50) \dagger$ \\
seizures $(\mathrm{n}=2)$ & 0 & 0 & $2(100)$ & 0 \\
hypopituitarism $(\mathrm{n}=1)$ & 0 & 0 & $1(100)$ & 0 \\
\hline
\end{tabular}

* Although 61 patients had visual loss, outcome is given for the 56 patients with available ophthalmological evaluation postoperatively.

$\dagger$ An elderly patient with multiple complications who died.

tumor location did not reach statistical significance $(\mathrm{p}=$ 0.09). Meningioma extension into the optic canal, which represents a challenge during traditional craniotomy, was not a limitation for GTR with EES.

The factors that significantly limited the surgical success of EES were tumor size, shape of the free surface of the meningioma, and vascular encasement ( $<<0.0001)$. Tumor size was significant when using for comparison a mean diameter of either $2.3 \mathrm{~cm}$ (average diameter) or 3 $\mathrm{cm}$. Multilobular tumor configuration may reflect more aggressive tumors with invasion of the pia and lack of arachnoid plane; based on this, a lower GTR rate would be expected compared with tumors with a rounded surface and clear arachnoid plane, in which the GTR rate was greater than $90 \%$ regardless of their size. In our experience, vascular encasement decreased the GTR rate of EES to $31.6 \%$, vs $91.1 \%$ when arteries are not encapsu- lated by the tumor (Fig. 3). Indeed, 13 of 19 meningiomas with vascular encasement had residual tumor, which was localized on the ACA complex in 8 cases (61.5\%), surrounding the supraclinoid carotid artery in 2 cases $(15.4 \%)$, and at the lateral margin of the meningioma in 3 cases $(23.1 \%$, representing large tumors with lateral extension more than vascular encapsulation).

To understand the impact of the learning curve in achieving GTR of suprasellar meningiomas, we separated the cohort into 5 sequential groups of 15 patients each and studied the 3 parameters that significantly influenced the surgical outcome in every quintile. As shown in Fig. 4, the GTR rate was high $(73 \%)$ in the 1st quintile, but those patients had been carefully selected to have small, rounded tumors without vascular involvement. When the tumors became more complex (2nd quintile) the GTR rate dropped dramatically, to $60 \%$. Without selection bias

TABLE 5: Rates of GTR according to specific tumor parameters in the entire cohort of 75 patients with suprasellar meningiomas

\begin{tabular}{|c|c|c|c|}
\hline Parameters & No. of Cases & No. w/ GTR (\%) & $p$ Value \\
\hline \multicolumn{4}{|l|}{ location } \\
\hline planum & 10 & $7(70.0)$ & 0.09 \\
\hline tuberculum & 37 & $32(86.5)$ & \\
\hline planum/tuberculum & 28 & $18(64.3)$ & \\
\hline \multicolumn{4}{|l|}{ extension } \\
\hline optic canal & 20 & $18(90.0)$ & 0.13 \\
\hline no-optic canal & 55 & $39(70.9)$ & \\
\hline \multicolumn{4}{|l|}{ maximum diameter } \\
\hline$\leq 2.3 \mathrm{~cm}$ & 42 & $41(97.6)$ & $<0.0001$ \\
\hline$>2.3 \mathrm{~cm}$ & 33 & $16(48.5)$ & \\
\hline$\leq 3 \mathrm{~cm}$ & 65 & $55(84.6)$ & $<0.0001$ \\
\hline$>3 \mathrm{~cm}$ & 10 & $2(20.0)$ & \\
\hline \multicolumn{4}{|l|}{ shape } \\
\hline rounded & 52 & $47(90.4)$ & $<0.0001$ \\
\hline multilobular & 23 & $10(43.5)$ & \\
\hline \multicolumn{4}{|l|}{ vascular encasement } \\
\hline no & 56 & 51 (91.1) & $<0.0001$ \\
\hline yes & 19 & $6(31.6)$ & \\
\hline total & 75 & $57(81.4)^{*}$ & \\
\hline
\end{tabular}

\footnotetext{
* Rate evaluated among 70 cases in which GTR was the goal of surgery.
} 

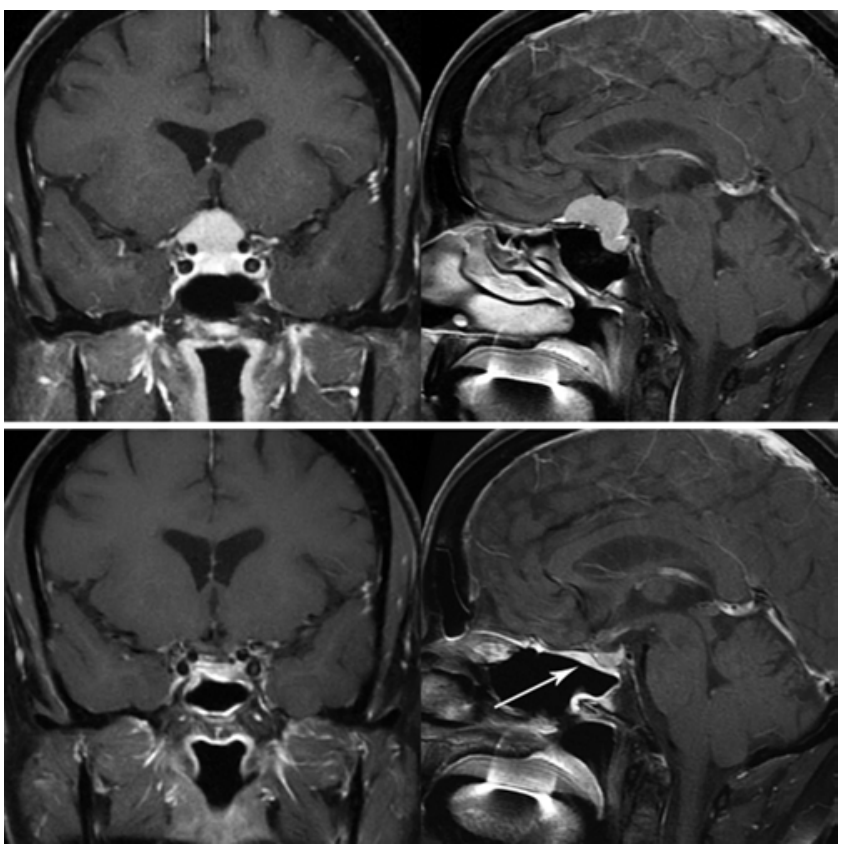

FIG. 2. Planum/tuberculum meningioma managed with EES. Upper: Preoperative coronal and sagittal MRI studies obtained after contrast administration illustrate a rounded meningioma with maximum diameter of $2.5 \mathrm{~cm}$ occupying the planum sphenoidale and tuberculum sellae, with extension into the right optic canal (not shown in these images). Lower: Postoperative coronal and sagittal MRI studies obtained after contrast administration demonstrate GTR of the tumor after EES. The linear enhancing area within the sphenoid sinus (arrow) represents the vascularized nasoseptal flap that was used for the reconstruction of the skull base.

and with increased experience the GTR rates show a progressive improvement, with GTR reaching $87 \%$ in the last quintile of patients. However, the improvement of GTR rates during the years in which selection bias was not applied does not reach significance $(p=0.47)$.

\section{Complications and Management}

The most common surgical complication was postoperative CSF leaks, which occurred in 19 patients $(25.3 \%)$ (Table 6). It is important to notice the decrease of this rate from $69.2 \%$ to $16.1 \%$ in recent years after the routine use of the vascularized nasoseptal flap for skull base reconstruction, and the further decrease to $11.7 \%$ during the last 2 years of our experience. The difference of CSF leak rates between the years with and without the vascularized flap was significant ( $<<0.0001)$ (Fig. 5). A CSF leak was usually managed with reexploration; it spontaneously resolved in 1 case and after lumbar drain placement in another; it required a single repeat EES in 11 patients (combined with lumbar drain in 4) and multiple repeat EESs in 6 patients (combined with lumbar drain in 4). The overall rate of postoperative meningitis following CSF leak was 5.3\%, all cases of which were treated with antibiotics without further complications. Two cases of postoperative hydrocephalus were managed with ventriculoperitoneal shunt placement.

Other medical complications included syndrome of inappropriate antidiuretic hormone (SIADH) secretion in 4
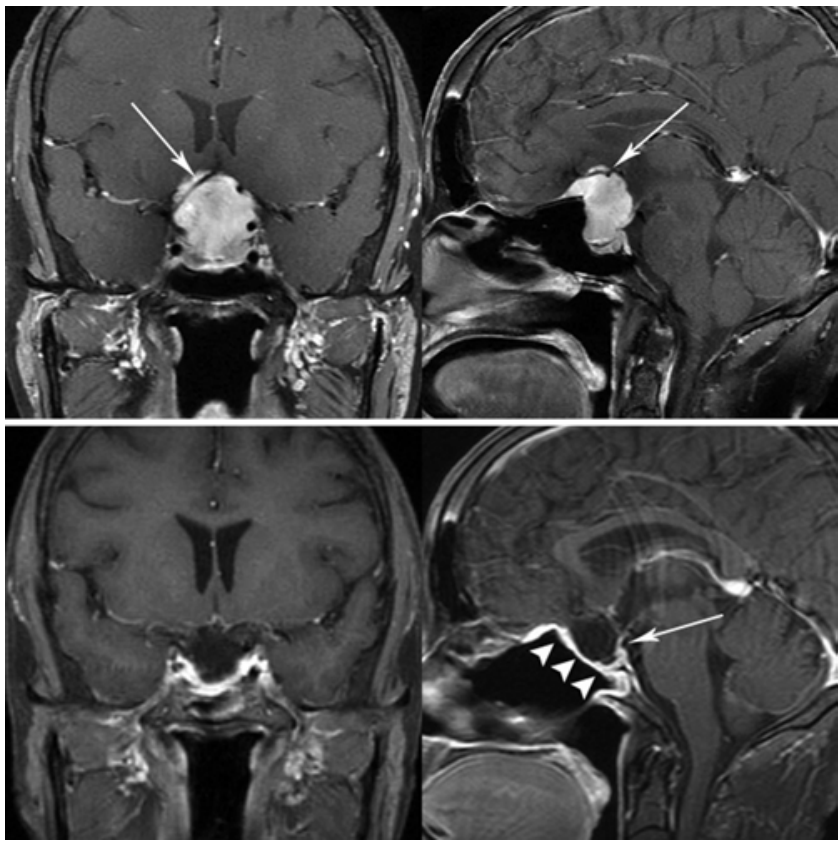

Fig. 3. Tuberculum sellae meningioma with engulfment of the ACA managed with EES. Upper: Preoperative coronal and sagittal MRI studies obtained after contrast administration show a tuberculum sellae meningioma that occupies the sella turcica, extends to the planum sphenoidale, and encapsulates the right ACA (arrows). Lower: Postoperative coronal and sagittal MRI studies obtained after contrast administration demonstrate the GTR of the tumor after EES. The pituitary stalk is visualized in the midline (arrow). An enhancing, vascularized nasoseptal flap was used for reconstruction of the skull base (arrowheads).

patients that resolved with water restriction; 1 patient with pulmonary embolism was treated with anticoagulation and vena cava filter placement; and 1 with respiratory failure required a tracheostomy for several days. The patient who presented with hypopituitarism developed permanent diabetes insipidus after EES; there were no cases with new postoperative hypopituitarism. One patient had a stroke due to intraoperative injury of the artery of Heubner, and 1 elderly patient died of multiple, unexplained cerebral infarcts and multisystem organ failure. One patient experienced a single episode of seizure in the immediate postoperative period and did not require long-term anticonvulsant therapy. Permanent visual deterioration following EES occurred in 2 patients $(3.6 \%)$ among 56 with available ophthalmological evaluation postoperatively-because of ischemia in one case (managed with repeat EES for exploration and papaverine instillation into the suprasellar system) and due to hemorrhage into a residual tumor in the second case (managed with repeat EES for hematoma evacuation); in both cases vision remained unchanged in long-term follow-up. Table 6 summarizes the complications in the whole cohort and also separately in the preflap and postflap era.

\section{Recurrence and Follow-Up}

During a mean follow-up period of 29 months (median 19 months, range 1-98 months), 4 patients (5.3\%) showed tumor recurrence; 3 of them had undergone near total resection and 1 had a GTR. The mean recurrence-free period 


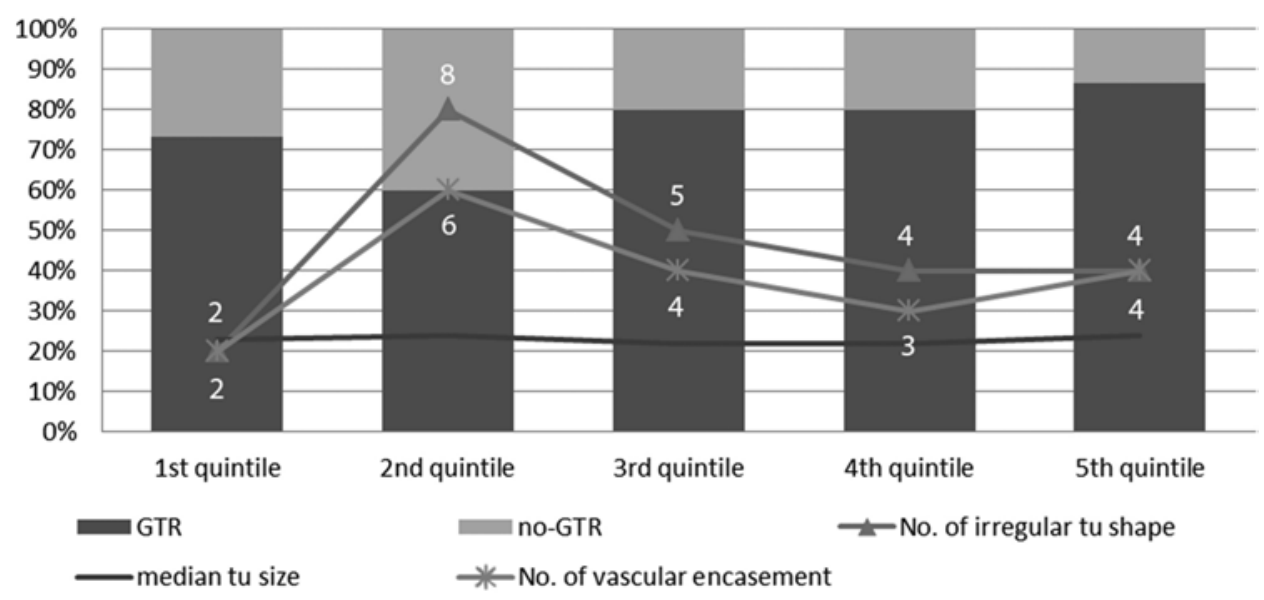

FIG. 4. Bar graph showing the impact of the learning curve in GTR of suprasellar meningiomas in quintiles of patients. The cohort of 75 patients was separated in 5 groups of 15 patients each who were surgically treated in chronological order. The 3 parameters that significantly influenced the surgical outcome (tumor [tu] size, irregular shape, and vascular encasement) were evaluated for every quintile of patients. The median tumor size remained almost stable (varying between 2.2 and $2.4 \mathrm{~cm}$ ), but the number of irregularly shaped tumors and cases of vascular encasement (presented in the graph next to the relevant parameter) increased after the 1st quintile of patients with the loss of selection bias. As a result, the GTR rate dropped after the 1st quintile and then progressively increased thereafter.

was 29.8 months (range 12-56 months). One patient was treated with repeat EES and was free of tumor at the most recent follow-up; 1 underwent radiosurgery and the recurrent tumor remains stable at 96-month follow-up; the other 2 patients with small recurrences remain asymptomatic.

\section{Discussion}

Successful resection of anterior skull base meningiomas has undergone a steady evolution parallel to the evolution of skull base techniques. The use of the operating microscope in contemporary skull base approaches has greatly improved surgical outcomes. ${ }^{7,18,46}$ The goal of cranial base approaches is to remove superficial bone to increase surgical access and totally resect anterior skull base meningiomas with minimal brain retraction, with minimal risk of optic nerve damage or vascular injury, and acceptable cosmetic results.

\section{Surgical Approaches and Limitations}

Currently, the most common traditional approaches for suprasellar meningiomas fall into 2 main categories: anterior (subfrontal) and lateral (pterional or frontotemporal) approaches. Each of these has its own set of possible modifications (orbital or orbitozygomatic osteotomies), advantages, and limitations. ${ }^{4}$

Subfrontal Craniotomy. The unilateral or bilateral subfrontal approach for the treatment of suprasellar meningiomas has been previously described in detail. 2,7,45,46 The advantages of this approach are visualization of both sides of the tumor and direct view of both optic nerves, supraclinoid carotid arteries, and the ACA complex after tumor resection. However, this approach usually requires some degree of frontal lobe retraction (whether dynamic or static) for adequate tumor exposure. Other disadvantages include possible venous infarction due to occlusion of

TABLE 6: Complications after EES

\begin{tabular}{lccc}
\hline \multicolumn{1}{c}{ Complication } & No. of Cases (\%) & $\begin{array}{c}\text { No. in Pre-Flap Era, } \\
\text { 2002-2005 (\%) }\end{array}$ & $\begin{array}{c}\text { No. in Post-Flap Era, } \\
\text { 2006-2011 (\%) }\end{array}$ \\
\hline no. of pts & 75 & 13 & 62 \\
CSF leak & $19(25.3)$ & $9(69.2)$ & $10(16.1)$ \\
meningitis (post-CSF leak) & $4(5.3)$ & $1(7.7)$ & $3(4.8)$ \\
SIADH secretion & $4(5.3)$ & 0 & $4(6.4)$ \\
visual deterioration* & $2(3.6)$ & 0 & $2(4.4)$ \\
hydrocephalus & $2(2.7)$ & 0 & $2(3.2)$ \\
diabetes insipidus (permanent) & $1(1.3)$ & 0 & $1(1.6)$ \\
Heubner artery injury & $1(1.3)$ & 0 & $1(1.6)$ \\
seizures, single episode & $1(1.3)$ & 0 & $1(1.6)$ \\
pulmonary embolism & $1(1.3)$ & 0 & $1(1.6)$ \\
respiratory failure & $1(1.3)$ & 0 & $1(1.6)$ \\
\hline
\end{tabular}

* Determined with postoperative visual tests that were available in 56 patients in the whole cohort and in 45 in the post-flap era. 


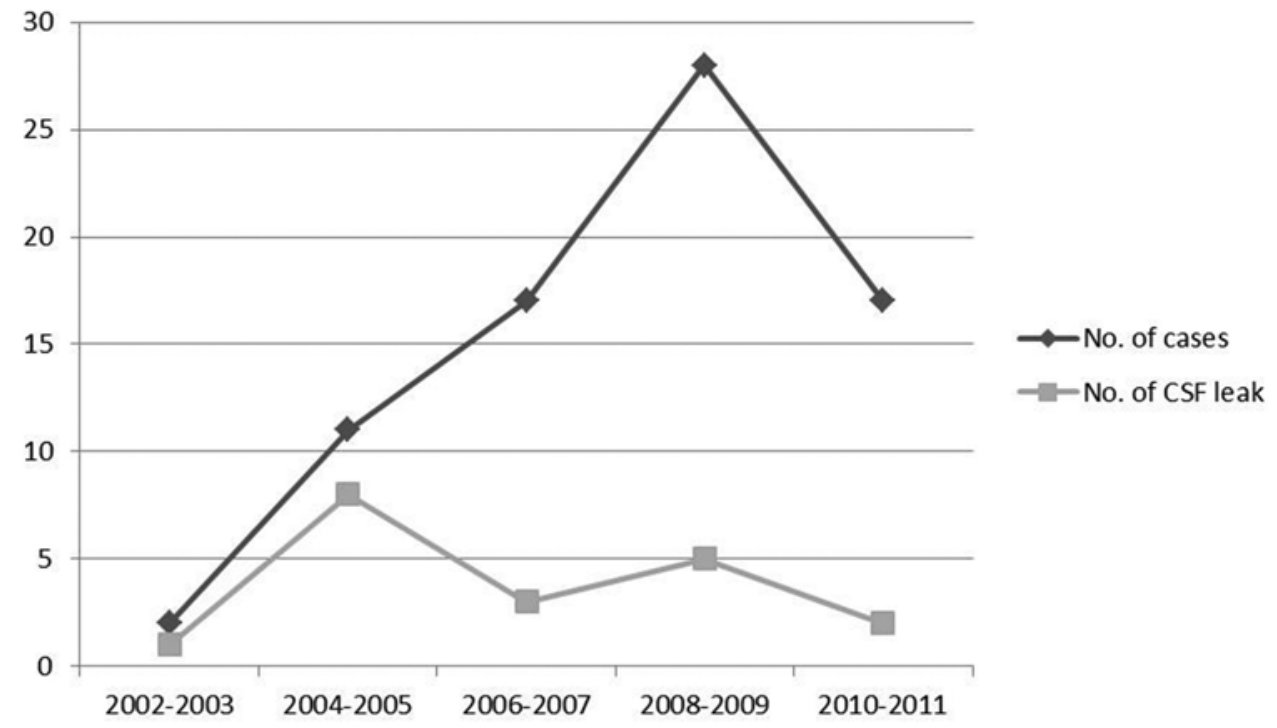

FIG. 5. Graph showing the time distribution of patients with suprasellar meningioma treated with EES and the number of CSF leak cases. After 2006 when the use of the vascularized flap became routine in skull base reconstruction, and regardless of the continuous increase in the number of patients treated with EES, the number of CSF leak cases dramatically decreased ( $p<$ 0.0001). The CSF leak rate was $69.2 \%$ in the early years, decreased to $16.1 \%$ after 2006 , and further declined to $11.7 \%$ during 2010-2011.

the superior sagittal sinus (in bilateral exposure), potential loss of olfaction, late visualization of vital neurovascular structures, and difficulty in reaching the undersurface of the optic nerves or the intrasellar extension of the tumor. Pursuing a unilateral subfrontal trajectory, the eyebrow supraorbital craniotomy has been advocated as a minimally invasive technique for suprasellar meningiomas. ${ }^{25}$

Pterional Craniotomy. The pterional or frontolateral approach became popular with the development of microsurgical techniques. ${ }^{4,18,23,27,40,43}$ It has the advantage of early exposure of the ipsilateral supraclinoid carotid artery, optic nerve, and ACA, with CSF draining from the opticocarotid cistern and decreased brain retraction. However, visualization of the contralateral side of the tumor and the medial aspect of the ipsilateral optic nerve and carotid artery might be inadequate. Also, invasion of the optic canal (especially when bilateral) and intrasellar extension of the tumor represent significant challenges.

Endoscopic Endonasal Surgery. The surgical technique of the EEA for anterior skull base tumors has already been described in detail. 5,6,8,13-15,21,28,39,44 Important advantages of EES such as lack of brain retraction, fast recovery, avoidance of cutaneous incisions with excellent cosmetic result, and shorter surgical time and hospital stay have been described.

There are several inherent advantages of the EEA. All abnormal bone underlying the tumor is removed during the approach. Although hyperostotic bone deformities may camouflage the anatomical landmarks of the skull base (sella, carotid protuberance, optic protuberance, medial and lateral opticocarotid recess, tuberculum sellae, and planum sphenoidale), the use of image guidance can prevent disorientation and provide precision in defining the bony boundaries (Fig. 6). When involved, the poste- rior ethmoidal arteries and other parasellar meningeal vessels can be identified and coagulated. This direct approach from below facilitates an early devascularization of tuberculum and planum meningiomas, resulting in an almost bloodless intracranial tumor removal, and fa-
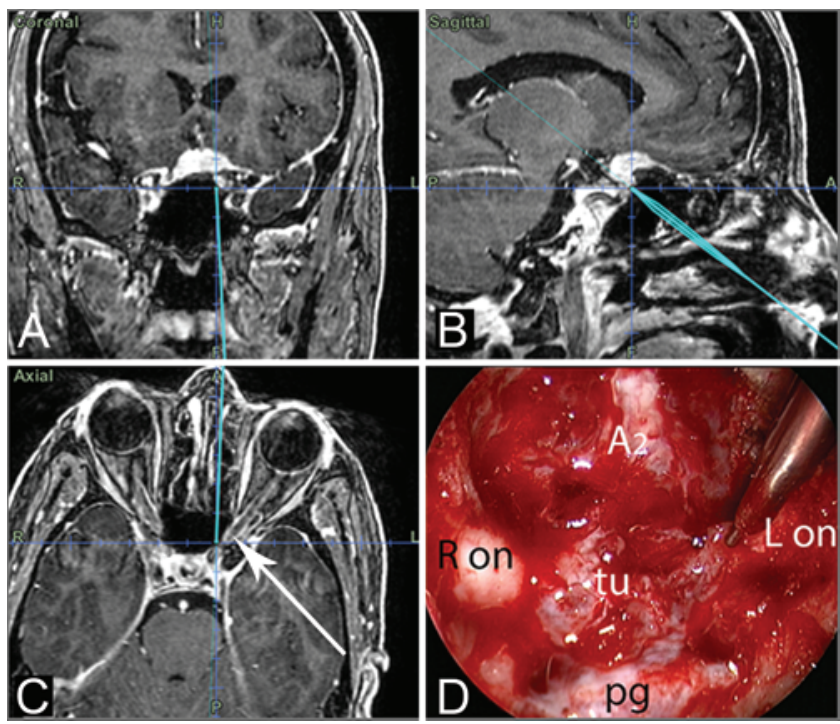

FIG. 6. Intraoperative images of a tuberculum sellae meningioma with invasion of the left optic canal obtained during resection with the use of image guidance. The left optic canal has been skeletonized and decompressed. A-C: Intraoperative MRI studies. The tumor (tu) that invaded the left optic canal (better seen on the coronal MRI) has already been removed and the pointer of the image guidance system is placed on the medial aspect of the left optic nerve ([L on], arrow on the axial MRI). The dura of the planum spenoidale has been resected, together with the dural tail of the meningioma. D: Endoscopic view. The pituitary gland $(\mathrm{pg})$ remains covered and protected by the sellar dura. The $A_{2}$ segment of the ACA is visualized above the remaining tumor. $\mathrm{R}$ on $=$ right optic nerve. 
cilitates complete resection of the sellar dural diaphragm where tuberculum sellae meningiomas may attach.

When the optic canal is involved, a $270^{\circ}$ decompression of the intracanalicular optic nerve is performed by removing the medial wall, floor, and roof of the canal. The falciform ligament and intracanalicular dura are sectioned from medial to lateral, allowing removal of the tumor within the canal without any manipulation of the optic nerve, and resulting in 90\% GTR in our experience. As demonstrated by others, total resection of midline anterior fossa meningiomas involving the optic canals is better facilitated with an anterior approach, such as the supraorbital..$^{34,47}$ Our retrospective study found that the pattern of tumor extension in the optic canal is into the medial aspect of the canal in every suprasellar meningioma. Thus, the midline EEA is the ideal approach for medial decompression of the optic canals and resection of the tumor without osteotomy of the orbital rim or resection of the orbital roof (with the potential risk of cosmetic deformities) as is required during a supraorbital approach (Fig. 6). Indeed, this pattern of optic canal invasion favors the midline EEA, which allows early extradural optic canal decompression even in cases of extensive hyperostosis due to bone invasion by meningioma. Care must be taken to identify a medially curving ophthalmic artery, but all optic nerve manipulation is obviated.

As a result of this direct approach to the tumor, EES minimizes the risk of postoperative visual loss, which is largely related to the delicate vascularization of the optic chiasm and nerves and/or manipulation of these structures. ${ }^{1,6,47}$ Given that the ACA complex provides the blood supply to the superior and dorsal surface of the optic nerves/chiasm and that the superior hypophyseal artery supplies their inferior surface, optic nerve/chiasm damage due to ischemia from the ACA complex might be prevented better with the EEA than with any transcranial route. ${ }^{6,41}$ Additionally, the superior hypophyseal artery can be better visualized and preserved with an approach from below. The EEA provides direct visualization of the neurovascular structures of the suprasellar and infrachiasmatic region from below (Fig. 7), allowing for a safe GTR with minimal neurovascular manipulations.

Staging remains a wise adjunct during initial application of endonasal surgery. It mainly reflects the learning curve associated with this challenging approach and also represents a standard skull base philosophy of applying staging to limit anesthesia time and surgeon fatigue. One advantage of EES is ease of staging, with immediate tumor exposure and ability to reuse the nasoseptal flap. ${ }^{50}$ Many of the staged cases in our study would have been treated with a single EEA nowadays, and indeed, since 2009 we have not applied staging for suprasellar meningiomas regardless of tumor size. After extensive experience with EES, the only indication for staging surgeries in suprasellar meningioma treatment is a tumor's extension lateral to the optic nerve, in which case an open approach at a second stage would be indicated.

\section{Surgical Outcome}

Gross-Total Resection. A GTR remains the goal

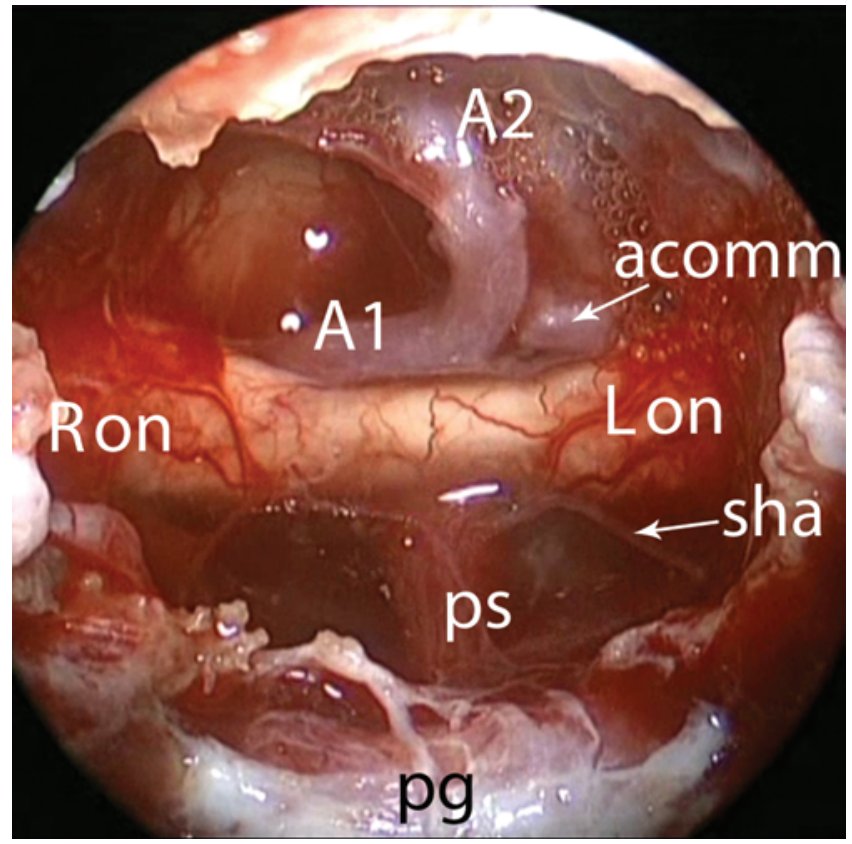

FIG. 7. Intraoperative image obtained with the $0^{\circ}$ endoscope after GTR of the tuberculum sellae meningioma from Fig. 6. The pituitary gland remains intact, covered by the sellar dura. The optic nerves (Ron, Lon) are visualized bilaterally free of tumor. The superior hypophyseal arteries (sha) located directly under the optic chiasm and feeding the optic chiasm, pituitary stalk (ps), and gland have been preserved bilaterally. The ACA complex with the $A_{1}$ and $A_{2}$ segments of the ACA and the anterior communicating artery (acomm) are visualized above the optic chiasm free of tumor. All the skull base dural attachments and the hyperostotic bone have been removed without manipulation of the visualized structures.

of meningioma surgery in most cases regardless of approach. However, GTR should be tempered by the risk of morbidity, such as visual deterioration in suprasellar meningioma surgery. ${ }^{9,18}$ Evaluation of the degree of tumor resection among published series of suprasellar meningiomas is not always straightforward because of the different definitions of "complete" resection., $718,27,37,38,46$ Symon and Rosenstein, ${ }^{46}$ in their experience with 101 suprasellar meningiomas treated mainly with the subfrontal craniotomy (either macroscopic or microscopic), had an overall complete resection rate of $78.2 \%$, which is based on the surgeon's impression and without postoperative MRI to confirm the lack of residual tumor. Fahlbusch and $\mathrm{Schott}^{18}$ have reported the impressive complete resection rate of $97.9 \%$ when using the pterional approach, but again without postoperative MRI in every case and without association of the degree of resection with the Simpson grading system. Jallo and Benjamin ${ }^{27}$ achieved a total tumor resection rate of $87 \%$ following pterional craniotomy, but again without reference to the Simpson grading system. Other authors have published complete resection rates in tuberculum sellae meningiomas of up to $91.7 \%$ (including, however, both Simpson Grade I and Grade II in their statistics). ${ }^{7,37}$

Using the traditional Simpson grading system for removal of meningiomas, we defined GTR as Grade I only. Also, we confirmed the lack of residual meningioma in every case with postoperative MRI, which is critical for 
Endoscopic endonasal surgery for suprasellar meningiomas

TABLE 7: Literature review comparing surgical outcome in the largest published series of suprasellar meningiomas*

\begin{tabular}{lclccccc}
\hline \multicolumn{1}{c}{ Authors \& Year } & No. of Pts & Surgical Approach & \% w/ GTR & $\begin{array}{c}\text { Simpson } \\
\text { Grade }\end{array}$ & $\begin{array}{c}\text { \% w/ Visual } \\
\text { Improvement }\end{array}$ & $\begin{array}{c}\text { \% w/ Visual } \\
\text { Deterioration }\end{array}$ & \% Mortality \\
\hline Symon \& Rosenstein, 1984 & 101 & $\begin{array}{c}\text { subfrontal cranio mainly } \\
\text { (macro/microscopic) }\end{array}$ & $78.2 \dagger$ & NR & 63.3 & 24.2 & 5.9 \\
Ciric \& Rosenblatt, 2001 & 24 & frontotemporopterional & $66.7 \dagger$ & NR & NA & 4.2 & 0.0 \\
Goel et al., 2002 & 70 & unilat subfrontal mainly & 84.3 & NR & 69.8 & 10.0 & 2.9 \\
Fahlbusch \& Schott, 2002 & 47 & pterional & $97.9 \dagger$ & NR & 80.0 & 20.0 & 0.0 \\
Schick \& Hassler, 2005 & 53 & pterional & $90.6+$ & NR & 44.4 & 13.5 & 3.7 \\
Nakamura et al., 2006 & 72 & mixed & 91.7 & I \& II & 67.9 & 12.5 & 2.8 \\
Mahmoud et al., 2010 & 58 & supraorbital & 87.9 & I & 74.0 & 8.0 & 1.7 \\
Chokyu et al., 2011 & 34 & subfrontal & 79.4 & I \& II & 90.6 & 0.0 & 0.0 \\
present study & 75 & EES & $81.4 \ddagger$ & I & 85.7 & 3.6 & 1.3 \\
\hline
\end{tabular}

* cranio = craniotomy; NA = not available; NR = not reported.

$\dagger$ Based on surgeon's impression; no postop MRI in every case.

$\ddagger$ Outcome when GTR was the goal of surgery.

objective evaluation of resection. With these criteria, the GTR rate for EES is $81.4 \%$ when GTR is the goal of surgery. This is in line with the largest published series even though the same strict criteria are not applied in all of them (Table 7). Endoscopic endonasal surgery is an ideal technique for resection of suprasellar meningiomas involving the optic canal, with GTR of $90 \%$ in this subcategory, as discussed above. Although a direct comparison between open and endoscopic surgeries for tuberculum sellae and planum sphenoidale meningiomas is difficult, a recent meta-analysis by Komotar et al. showed that degree of tumor resection is significantly different between the 2 approaches, with open surgeries being superior to endoscopic (84.1\% of GTRs achieved with open surgeries vs $74.7 \%$ of GTRs with EES). ${ }^{30}$ However, the available data in the literature represent the early experience of the recently developed EES, and the learning curve of this technique must not be overlooked.

Factors that limit tumor removal with EES are factors that increase risk and difficulty with traditional approaches as well. Based on the statistical analysis of our results as presented in Table 5, tumor size is an important factor that can limit GTR, especially for tumors larger than $3 \mathrm{~cm}$. This is not a limitation only for EES; various authors have considered the size of the tumor to be a crucial factor that indicates possible surgical difficulties. ${ }^{9,22,45,46}$ Symon and Rosenstein clearly demonstrate a better overall outcome for tumors smaller than $3 \mathrm{~cm}$, and Fahlbusch and Schott notice that in large tumors the arachnoid plane may not be intact, which can contribute to the risk of vascular injuries and postoperative visual deterioration. ${ }^{18,46}$ Multilobular tumor configuration, possibly reflecting more aggressive meningiomas with invasion of the pia and lack of arachnoid plane, has also limited the resection rates with EES. Because the key to safe removal of suprasellar meningiomas is to keep the surgical dissection plane strictly along the tumor-arachnoid interface, aggressive meningiomas with pial invasion represent challenging tumors to treat regardless of the surgical approach..$^{9,18,22,34,47}$ By the same means, vas- cular encasement, which has significantly decreased the GTR rates with EES, carries a significant risk of vascular injury and represents a surgical challenge with any approach. ${ }^{7,919,22,32,46}$ Given the limitations found in this review, large tumors with vascular encasement should be considered for a transcranial approach, especially early in an endoscopic team's experience. In the end, the approach should be chosen based on the individual surgeon's comfort and ability to provide maximal results for each individual patient.

It is worth noting that at the time of this publication, every patient with a midline, suprasellar meningioma who is referred to our skull base team is treated with EES regardless of the tumor size, extension, or configuration; no patients were treated with open approaches as the initial management, and we believe this is the most important factor to limit selection bias in the recent years of the study. However, during the early years and while gaining experience with EES, patients were carefully selected, and this explains the different resection rates over the years as described below. The only exception among suprasellar meningiomas that are not candidates for EES are these originating from the anterior clinoid-thus lateral to the optic nerve-these tumors cannot be totally resected with a midline approach and should be treated with a traditional craniotomy. By these criteria, we used craniotomy as a second-stage approach following EES in only 1 patient with residual tumor located lateral to the optic nerve.

The learning curve is always an important factor that influences the surgical outcome, especially in the application of a new technique such as EES. As illustrated in Fig. 4, when selection bias was excluded after the first cases, the GTR rates progressively improved. However, the improvement of GTR rates following EES of suprasellar meningiomas over time was not as impressive as with other tumors in more demanding locations (such as skull base chordomas). ${ }^{31}$ This probably reflects the relative familiarity of surgeons with the sellar/suprasellar anatomy compared with the clival/paraclival area, as well as the size and invasiveness of other tumors. 


\section{Koutourousiou et al.}

Visual Outcome. As shown in Table 7, the rate of visual improvement after EES was among the highest reported in the literature (85.7\%). Of note, these results are based on postoperative visual testing and do not only represent subjective visual improvement as reported by the patients. The inferior-to-superior trajectory that the EEA provides, with the resultant ability to remove tumors compressing the optic nerves/chiasm without their manipulation, as well as the excellent visualization and attendant preservation of microvasculature provided by the endoscope are probably the main reasons for these results. ${ }^{3,5,6,13-15,19,21,28,48}$ As a special note, $94.1 \%$ of patients with tumor extension into the optic canal had improved vision after EES, due to optic nerve decompression and resection of the intracanalicular tumor. As mentioned in the Methods, we define optic canal involvement as tumor extension to the lateral opticocarotid recess, in contrast to other reports with less strict criteria that consider optic canal invasion to include any tumor that extends into the entrance to the canal (which is still technically in the cistern) ${ }^{42,47}$ We think that this difference in the definition of optic canal involvement is meaningful because true optic canal invasion would always require removal of the medial wall of the optic canal beyond the anterior aspect of the optic strut (or lateral opticocarotid recess) and subsequent opening of the medial dural wall of the canal, which can safely and effectively be achieved with EES. The technique of unroofing the optic canal via a supraorbital craniotomy resulted in $74 \%$ visual improvement, which may be expected given the difficulty involved in using any transcranial approach to access and widely decompress the medial and inferomedial aspect of the optic canal (where tumor most commonly invades)..$^{34}$

The literature on transcranial approaches has illustrated the importance of early optic canal decompression and its results in improving visual outcomes by avoiding manipulation of a tethered optic nerve during tumor resection..$^{34,35,38}$ This has been incorporated into EES and is a standard part of our current exposure. The removal of the medial, inferior, and superior walls of the optic canal(s), when needed based on preoperative imaging, is part of the surgical approach and is completed before any tumor manipulation. Indeed, the optic canals are easily accessible from an endonasal route, even more than the transcranial route. This early optic canal decompression may be another reason for the higher rate of visual improvement with EES. Similar favorable results have been reported by other authors who used EES and were confirmed in a recent meta-analysis in which the results of open and endonasal surgeries for anterior skull base meningiomas were compared; the rate of visual improvement was found to be higher with EES $(69.1 \%$ vs $58.7 \%$ after open approaches). . $^{3,5,6,13-15,30,33,48}$ Although some authors have described that postoperative visual outcome is affected by tumor size, with better results when tumor was $<2.5 \mathrm{~cm}$, in our experience tumor size was not a significant factor in postoperative visual improvement $(\mathrm{p}$ $=0.26$, when comparing visual improvement between tumors $\geq 2.5 \mathrm{~cm}$ and $<2.5 \mathrm{~cm}) .{ }^{47}$ However, other factors, like the duration of preoperative visual symptoms, the degree of preoperative visual impairment, and patients' age, have been correlated with the postoperative visual outcome..$^{36,43}$

\section{Surgical Complications}

The most challenging aspect in suprasellar meningioma surgery is achieving total resection without risking visual deterioration due to manipulation or interruption of the vasculature of the optic nerves/chiasm. $6,7,18,21,34,47$ Symon and Rosenstein ${ }^{46}$ in their experience with mainly macroscopic craniotomies, had a vision deterioration rate of $24.2 \%$. Although microscopic techniques have greatly improved outcomes, most of the publications in the microscopic era still describe a significant rate of visual worsening. Fahlbusch and Schott, ${ }^{18}$ using the pterional approach with high complete resection rates, noted postoperative visual deterioration in $20 \%$ of their cases. Jallo and Benjamin ${ }^{27}$ noticed visual deterioration in $19 \%$ of their cases following use of the pterional approach. The supraorbital approach used by Mahmoud et al. ${ }^{34}$ specifically for tuberculum meningiomas with invasion of the optic canal resulted in $8 \%$ postoperative visual decline. We consider the inferior-to-superior trajectory provided by the EEA to be the most important factor to enhance preservation of the optic nerve/chiasm and their feeding branches (Fig. 7). As a result of these advantages, visual deterioration occurred in only $3.6 \%$ of patients after EES.

A CSF leak after craniotomy for resection of suprasellar meningiomas usually occurs via the frontal sinus.? Various reconstruction techniques have been suggested to prevent CSF leaks and resultant meningitis, with the use of pericranial flap with or without adipose tissue being the most popular. $918,22,34,37$ Symon and Rosenstein ${ }^{46}$ noticed a CSF leak rate of $4 \%$ with the subfrontal approach. In a series with mixed approaches, CSF leaks occurred in $4.2 \% .{ }^{37}$ The experience with pterional craniotomy, as described by Fahlbusch and Schott,,$^{18}$ resulted in a $6.4 \%$ rate of CSF leaks and the supraorbital approach, by Mahmoud et al.,$^{34}$ in $6.9 \%$.

The incidence of postoperative meningitis following craniotomy for suprasellar meningiomas is usually low (approximately 2\%), although cases of fatal meningitis have been described..$^{22,37}$ Komotar et al. ${ }^{30}$ found that postoperative CSF leak rates are significantly higher after endoscopic surgeries compared with open approaches. Indeed, EES is associated with higher CSF leak rates, which were extremely high before the use of the vascularized nasoseptal flap for skull base reconstruction, as shown in Table 6 . The evolution of the vascularized reconstruction technique has dramatically decreased the CSF leak rate to $16.1 \%(p<0.0001) .24,29,49$ Since 2010 the CSF leak rate has decreased to $11.7 \%$, and we expect to further improve this rate following EES.

Reconstruction techniques were in evolution throughout the course of this case series, as reflected in the dramatic decrease in CSF leak rates. There are still nuances that can be improved for even lower rates. There are several different, well-described techniques used by other groups with great success. ${ }^{3,20,48}$ We have not adopted rigid materials in our reconstruction due to increasingly wide bony exposures and decompression. There are reports of vascular injury from such implants, and after wide optic 


\section{Endoscopic endonasal surgery for suprasellar meningiomas}

nerve decompression there is no tissue against which to safely wedge an implant. ${ }^{12}$ Multilayer closures also hold merit and recapitulate open techniques. ${ }^{16,17}$ However, all of these have been supplemented successfully with vascularized tissue. This has become universally accepted as the critical step in successful endonasal skull base reconstruction, and the nasoseptal flap has become routine in recent years, with excellent results in preventing postoperative CSF rhinorrhea. In the post-flap era, postoperative meningitis occurred in $4.8 \%$ of our cases, and all were treated without further complications. Lumbar drain placement is often routine following EES, but its necessity is currently under investigation.

Other complications like SIADH secretion, diabetes insipidus, respiratory failure, and pulmonary embolism have been described following open approaches, usually in low rates, similar to our experience with EES. $9,22,37,46$ Postcraniotomy, new-onset seizures occurred in $10.9 \%$ of patients according to Symon and Rosenstein; ${ }^{46}$ unfortunately, this potential complication was not addressed in more recent publications. Following EES, no patient required treatment for new-onset seizures. The challenge of resecting suprasellar meningiomas when they encapsulate vascular structures has already been discussed. Arterial injuries during dissection have been described in craniotomy series, and on some occasions were fatal. ${ }^{22}$ In this series there was 1 case of vascular injury (artery of Heubner), which resulted in subtle but significant cognitive deficits.

Mortality following craniotomy for suprasellar meningiomas used to be higher in the premicroscope era (5.9\% in Symon and Rosenstein's experience), but these rates dropped below 3\% with the evolution of microscopic approaches, as shown in Table $7 .{ }^{46}$ However, mortality rates as high as $8.7 \%$ have been described even with microscopically aided dissections. ${ }^{27}$ In this endoscopic series, 1 death $(1.3 \%)$ occurred in an elderly patient with comorbidities, emphasizing the importance of careful patient selection and tempering of the goals of resection.

\section{Tumor Recurrences}

As stated by Fahlbusch and Schott, ${ }^{18}$ there are 4 main factors influencing the risk of known tumor recurrence: 1) extent of tumor resection; 2) histological grading of the tumor; 3) length of the postoperative follow-up period; and 4) mode and quality of the assessment of tumor recurrence. Unfortunately, the nascent application of EES does not allow for long-term follow-up yet. Thus, the recurrence rate in our series could not be used for comparison with the published series of open approaches for the treatment of suprasellar meningiomas. Nevertheless, during a mean follow-up period of 29 months (median 19, range 1-98 months), 4 patients (5.3\%) showed evidence of recurrence on high-resolution MRI (3 with growth of residual tumor and 1 after GTR). Only 1 of these became symptomatic and underwent repeat EES. The mean recurrence-free period was 29.8 months (range 12-58 months) and all lesions were WHO Grade I meningiomas. As expected, in recent series with the availability of MRI for follow-up, the identification of asymptomatic recurrent tumors is higher, resulting in an overall higher recur- rence rate. In the literature, recurrence rates of $0 \%-12 \%$ have been published, but the length of follow-up varies widely (from 3.2 to 10.6 years), and some authors report only symptomatic recurrences. ${ }^{18,37}$

\section{Study Limitations}

Besides the short follow-up in this series that does not allow for accurate evaluation of tumor recurrences, the strength of our study is limited by retrospective data collection in terms of selection bias, nonadjudicated outcomes, and the small subgroup cohorts that were analyzed.

\section{Conclusions}

Subsequent to the widespread adoption of the microscope in skull base surgery, the endoscope has started to gain popularity in the management of suprasellar meningiomas. Endoscopic endonasal surgery is a less externally invasive and more direct route to the suprasellar area. It is ideal for midline anterior skull base lesions such as tuberculum sellae and planum sphenoidale meningiomas, and converts these tumors into endonasal "convexity" meningiomas. Removal of involved bone, early tumor devascularization, resection of dural attachments, tumor debulking and dissection following the arachnoid planes with no brain retraction, preservation of optic apparatus vascularization, and no manipulation of severely compromised optic chiasm and nerves can facilitate GTR with minimal complications.

Based on the current data, EES represents a safe and efficient alternative to microscopic craniotomy for resection of suprasellar meningiomas. Visual outcomes appear to be favorable when compared with transcranial approaches, but with a tradeoff of increased CSF leak rates. A randomized controlled trial would be required to consolidate these results for similar tumor sizes and types, but this is unlikely to occur given the relative rarity of this tumor and current, strong surgical beliefs.

Continued studies, technological advances, and introduction of new techniques like the vascularized nasoseptal flap for skull base reconstruction have reduced the rate of CSF leaks, and they are expected to improve further. The EES option for suprasellar meningiomas requires extensive surgical experience and a dedicated multidisciplinary surgical team. Continued, longer-term follow-up studies are needed for the comparison of recurrence rates.

\section{Acknowledgments}

We are thankful to Tina Costacou, Ph.D., Assistant Professor of Epidemiology, University of Pittsburgh, for the statistical analysis of the surgical results. Also, we thank Dr. Amin B. Kassam, Division of Neurosurgery, University of Ottawa, Ontario, Canada; Dr. Ricardo L. Carrau at the Department of Otolaryngology-Head \& Neck Surgery; and Dr. Daniel M. Prevedello at the Department of Neurological Surgery, The Ohio State University Medical College, Columbus, Ohio, for their involvement in the clinical and operative management in many of these patients.

\section{Disclosure}

The authors report no conflict of interest concerning the mate- 
rials or methods used in this study or the findings specified in this paper.

Author contributions to the study and manuscript preparation include the following. Conception and design: Gardner, Koutourousiou, Fernandez-Miranda. Acquisition of data: Koutourousiou, Stefko. Analysis and interpretation of data: Koutourousiou. Drafting the article: Koutourousiou. Critically revising the article: Gardner, Koutourousiou, Fernandez-Miranda, Snyderman. Reviewed submitted version of manuscript: all authors. Approved the final version of the manuscript on behalf of all authors: Gardner. Study supervision: Gardner.

\section{References}

1. Al-Mefty O, Holoubi A, Rifai A, Fox JL: Microsurgical removal of suprasellar meningiomas. Neurosurgery 16:364-372, 1985

2. Arai H, Sato K, Okuda O, Miyajima M, Hishii M, Nakanishi $\mathrm{H}$, et al: Transcranial transsphenoidal approach for tuberculum sellae meningiomas. Acta Neurochir (Wien) 142:751-757, 2000

3. Attia M, Kandasamy J, Jakimovski D, Bedrosian J, Alimi M, Lee DL, et al: The importance and timing of optic canal exploration and decompression during endoscopic endonasal resection of tuberculum sella and planum sphenoidale meningiomas. Neurosurgery 71 (1 Suppl Operative):58-67, 2012

4. Bogaev CA, Sekhar LN: Olfactory groove and planum sphenoidale meningiomas, in Sekhar LN, Fessler RG (eds): Atlas of Neurosurgical Techniques. New York: Thieme Medical Publishers, 2006, pp 608-617

5. Cappabianca P, Cavallo LM, Esposito F, De Divitiis O, Messina A, De Divitiis E: Extended endoscopic endonasal approach to the midline skull base: the evolving role of transsphenoidal surgery. Adv Tech Stand Neurosurg 33:151-199, 2008

6. Cappabianca P, Cavallo LM, Esposito F, Solari D: Sellar/tuberculum approach, in Kassam AB, Gardner PA (eds): Endoscopic Approaches to the Skull Base. Progress in Neurological Surgery, Vol 26. Basel: Karger, 2012, pp 41-59

7. Chokyu I, Goto T, Ishibashi K, Nagata T, Ohata K: Bilateral subfrontal approach for tuberculum sellae meningiomas in long-term postoperative visual outcome. Clinical article. J Neurosurg 115:802-810, 2011

8. Chowdhury FH, Haque MR, Goel AH, Kawsar KA: Endoscopic endonasal extended transsphenoidal removal of tuberculum sellae meningioma (TSM): an experience of six cases. Br J Neurosurg 26:692-699, 2012

9. Ciric I, Rosenblatt S: Suprasellar meningiomas. Neurosurgery 49:1372-1377, 2001

10. Cook SW, Smith Z, Kelly DF: Endonasal transsphenoidal removal of tuberculum sellae meningiomas: technical note. Neurosurgery 55:239-246, 2004

11. Couldwell WT, Weiss MH, Rabb C, Liu JK, Apfelbaum RI, Fukushima T: Variations on the standard transsphenoidal approach to the sellar region, with emphasis on the extended approaches and parasellar approaches: surgical experience in 105 cases. Neurosurgery 55:539-550, 2004

12. Crowley RW, Dumont AS, Jane JA Jr: Bilateral intracavernous carotid artery pseudoaneurysms as a result of sellar reconstruction during the transsphenoidal resection of a pituitary macroadenoma: case report. Minim Invasive Neurosurg 52:4448, 2009

13. de Divitiis E, Cavallo LM, Cappabianca P, Esposito F: Extended endoscopic endonasal transsphenoidal approach for the removal of suprasellar tumors: Part 2. Neurosurgery 60:46-59, 2007

14. de Divitiis E, Cavallo LM, Esposito F, Stella L, Messina A: Extended endoscopic transsphenoidal approach for tuberculum sellae meningiomas. Neurosurgery 61 (5 Suppl 2):229_ 238, 2007

15. Dehdashti AR, Ganna A, Witterick I, Gentili F: Expanded endoscopic endonasal approach for anterior cranial base and su- prasellar lesions: indications and limitations. Neurosurgery 64:677-689, 2009

16. Eloy JA, Patel SK, Shukla PA, Smith ML, Choudhry OJ, Liu JK: Triple-layer reconstruction technique for large cribriform defects after endoscopic endonasal resection of anterior skull base tumors. Int Forum Allergy Rhinol 3:204-211, 2013

17. Eloy JA, Shukla PA, Choudhry OJ, Singh R, Liu JK: Challenges and surgical nuances in reconstruction of large planum sphenoidale tuberculum sellae defects after endoscopic endonasal resection of parasellar skull base tumors. Laryngoscope 123:1353-1360, 2013

18. Fahlbusch R, Schott W: Pterional surgery of meningiomas of the tuberculum sellae and planum sphenoidale: surgical results with special consideration of ophthalmological and endocrinological outcomes. J Neurosurg 96:235-243, 2002

19. Fernandez-Miranda JC, Pinheiro-Nieto C, Gardner PA, Snyderman $\mathrm{CH}$ : Endoscopic endonasal approach for a tuberculum sellae meningioma. J Neurosurg 32 Suppl:E8, 2012 (Video)

20. Garcia-Navarro V, Anand VK, Schwartz TH: Gasket seal closure for extended endonasal endoscopic skull base surgery: efficacy in a large case series. World Neurosurg 80:563-568, 2013

21. Gardner PA, Kassam AB, Thomas A, Snyderman CH, Carrau RL, Mintz AH, et al: Endoscopic endonasal resection of anterior cranial base meningiomas. Neurosurgery 63:36-54, 2008

22. Goel A, Muzumdar D, Desai KI: Tuberculum sellae meningioma: a report on management on the basis of a surgical experience with 70 patients. Neurosurgery 51:1358-1364, 2002

23. Gökalp HZ, Arasil E, Kanpolat Y, Balim T: Meningiomas of the tuberculum sella. Neurosurg Rev 16:111-114, 1993

24. Hadad G, Bassagasteguy L, Carrau RL, Mataza JC, Kassam A, Snyderman $\mathrm{CH}$, et al: A novel reconstructive technique after endoscopic expanded endonasal approaches: vascular pedicle nasoseptal flap. Laryngoscope 116:1882-1886, 2006

25. Hayhurst C, Teo C: Tuberculum sella meningioma. Otolaryngol Clin North Am 44:953-963, viii-ix, 2011

26. Honegger J, Fahlbusch R, Buchfelder M, Huk WJ, Thierauf P: The role of transsphenoidal microsurgery in the management of sellar and parasellar meningioma. Surg Neurol 39:18-24, 1993

27. Jallo GI, Benjamin V: Tuberculum sellae meningiomas: microsurgical anatomy and surgical technique. Neurosurgery 51:1432-1440, 2002

28. Kassam A, Snyderman CH, Mintz A, Gardner P, Carrau RL: Expanded endonasal approach: the rostrocaudal axis. Part I. Crista galli to the sella turcica. Neurosurg Focus 19(1):E3, 2005

29. Kassam AB, Thomas A, Carrau RL, Snyderman CH, Vescan A, Prevedello D, et al: Endoscopic reconstruction of the cranial base using a pedicled nasoseptal flap. Neurosurgery 63 (1 Suppl 1):ONS44-ONS53, 2008

30. Komotar RJ, Starke RM, Raper DM, Anand VK, Schwartz TH: Endoscopic endonasal versus open transcranial resection of anterior midline skull base meningiomas. World Neurosurg 77:713-724, 2012

31. Koutourousiou M, Gardner PA, Tormenti MJ, Henry SL, Stefko ST, Kassam AB, et al: Endoscopic endonasal approach for resection of cranial base chordomas: outcomes and learning curve. Neurosurgery 71:614-625, 2012

32. Levine ZT, Buchanan RI, Sekhar LN, Rosen CL, Wright DC: Proposed grading system to predict the extent of resection and outcomes for cranial base meningiomas. Neurosurgery 45:221-230, 1999

33. Liu JK, Christiano LD, Patel SK, Tubbs RS, Eloy JA: Surgical nuances for removal of tuberculum sellae meningiomas with optic canal involvement using the endoscopic endonasal extended transsphenoidal transplanum transtuberculum approach. Neurosurg Focus 30(5):E2, 2011 


\section{Endoscopic endonasal surgery for suprasellar meningiomas}

34. Mahmoud M, Nader R, Al-Mefty O: Optic canal involvement in tuberculum sellae meningiomas: influence on approach, recurrence, and visual recovery. Neurosurgery 67 (3 Suppl Operative):ons108-ons119, 2010

35. Mathiesen T, Kihlström L: Visual outcome of tuberculum sellae meningiomas after extradural optic nerve decompression. Neurosurgery 59:570-576, 2006

36. Mortini P, Barzaghi LR, Serra C, Orlandi V, Bianchi S, Losa M: Visual outcome after fronto-temporo-orbito-zygomatic approach combined with early extradural and intradural optic nerve decompression in tuberculum and diaphragma sellae meningiomas. Clin Neurol Neurosurg 114:597-606, 2012

37. Nakamura M, Roser F, Struck M, Vorkapic P, Samii M: Tuberculum sellae meningiomas: clinical outcome considering different surgical approaches. Neurosurgery 59:1019-1029, 2006

38. Nozaki K, Kikuta K, Takagi Y, Mineharu Y, Takahashi JA, Hashimoto N: Effect of early optic canal unroofing on the outcome of visual functions in surgery for meningiomas of the tuberculum sellae and planum sphenoidale. Neurosurgery 62:839-846, 2008

39. Padhye V, Naidoo Y, Alexander H, Floreani S, Robinson S, Santoreneos S, et al: Endoscopic endonasal resection of anterior skull base meningiomas. Otolaryngol Head Neck Surg 147:575-582, 2012

40. Pamir MN, Ozduman K, Belirgen M, Kilic T, Ozek MM: Outcome determinants of pterional surgery for tuberculum sellae meningiomas. Acta Neurochir (Wien) 147:1121-1130, 2005

41. Rhoton AL Jr: The supratentorial arteries. Neurosurgery 51 (4 Suppl):S53-S120, 2002

42. Sade B, Lee JH: High incidence of optic canal involvement in tuberculum sellae meningiomas: rationale for aggressive skull base approach. Surg Neurol 72:118-123, 2009

43. Schick U, Hassler W: Surgical management of tuberculum sellae meningiomas: involvement of the optic canal and visual outcome. J Neurol Neurosurg Psychiatry 76:977-983, 2005

44. Snyderman CH, Pant H, Carrau RL, Prevedello D, Gardner P, Kassam AB: What are the limits of endoscopic sinus sur- gery?: the expanded endonasal approach to the skull base. Keio J Med 58:152-160, 2009

45. Solero CL, Giombini S, Morello G: Suprasellar and olfactory meningiomas. Report on a series of 153 personal cases. Acta Neurochir (Wien) 67:181-194, 1983

46. Symon L, Rosenstein J: Surgical management of suprasellar meningioma. Part 1: The influence of tumor size, duration of symptoms, and microsurgery on surgical outcome in 101 consecutive cases. J Neurosurg 61:633-641, 1984

47. Taha AN, Erkmen K, Dunn IF, Pravdenkova S, Al-Mefty O: Meningiomas involving the optic canal: pattern of involvement and implications for surgical technique. Neurosurg Focus 30(5):E12, 2011

48. Van Gompel JJ, Frank G, Pasquini E, Zoli M, Hoover J, Lanzino G: Expanded endonasal endoscopic resection of anterior fossa meningiomas: report of 13 cases and meta-analysis of the literature. Neurosurg Focus 30(5):E15, 2011

49. Zanation AM, Carrau RL, Snyderman CH, Germanwala AV, Gardner PA, Prevedello DM, et al: Nasoseptal flap reconstruction of high flow intraoperative cerebral spinal fluid leaks during endoscopic skull base surgery. Am J Rhinol Allergy 23:518-521, 2009

50. Zanation AM, Carrau RL, Snyderman CH, McKinney KA, Wheless SA, Bhatki AM, et al: Nasoseptal flap takedown and reuse in revision endoscopic skull base reconstruction. Laryngoscope 121:42-46, 2011

Manuscript submitted April 14, 2013

Accepted February 11, 2014.

Please include this information when citing this paper: published online March 28, 2014; DOI: 10.3171/2014.2.JNS13767.

Address correspondence to: Paul A. Gardner, M.D., Department of Neurosurgery, University of Pittsburgh Medical Center Presbyterian, 200 Lothrop St., Ste. B400, Pittsburgh, PA 15213. email: gardpa@upmc.edu. 